\title{
PRODUÇÃO ACADÊMICA EM FUTSAL FEMININO: ESTADO DA ARTE DOS ARTIGOS CIENTÍFICOS NACIONAIS
}

${ }^{1}$ Ellen Hohana de Luna Macedo ${ }^{2}$ Jefferson Willian Santos do Nascimento ${ }^{3}$ Wesley Carlos Souza Silva ${ }^{4}$ Alison Oliveira da Silva

\section{RESUMO}

Introdução: No Brasil, o futsal é um esporte coletivo semelhante ao futebol possuindo suas peculiaridades e tornando-se uma modalidade praticada por um grande número de pessoas. Embora seja uma categoria ampla, o gênero feminino ainda sofre barreiras discriminatórias e machistas que por vezes tornam-se obstáculos para as atletas. Objetivo: Este estudo objetivou mapear a produção científica sobre futsal feminino no Brasil, por meio de uma revisão narrativa da literatura. Método: Considerando apenas artigos originais, que apresentassem alguma informação sobre o futsal feminino brasileiro, os dados foram coletados nas plataformas eletrônicas Scielo (Scientific Electronic Library Online), no Portal Regional da BVS e Portal Periódicos (CAPES). A busca inicial dos dados gerou 589 estudos, e todos foram importados para o Endnote versão 7.0 para triagem, apenas 36 atenderam aos critérios de elegibilidade. Resultados: Os estudos abrangeram oito temáticas diferentes e esses achados escancaram a enorme diferença ainda existente entre gêneros no esporte. Todavia, é possível identificar o crescimento no número de publicações referidas ao futsal feminino no Brasil nos últimos anos. Discussão: Sobre as principais temáticas investigadas as questões de "Gênero" têm sido inseridas nas publicações científicas, pois ser mulher e jogar futebol significa, simultaneamente, praticar um esporte concebido como fenômeno social. Conclusão: conclui-se que se faz necessário que pesquisas futuras sejam feitas para enriquecer a área, torná-la mais visível e minimizar a diferença entre os sexos.

Palavras-chave: Futsal feminino, Brasil, estado da arte.

\section{ACADEMIC PRODUCTION IN FEMALE FUTSAL: STATE OF THE ART OF NATIONAL SCIENTIFIC ARTICLES}

\begin{abstract}
Introduction: In Brazil, futsal is a team sport similar to soccer, having its peculiarities and becoming a sport practiced by a large number of people. Although it is a broad category, the female gender still suffers discriminatory and sexist barriers that sometimes become obstacles for female athletes. Objective: This study aimed to map the scientific production on women's futsal in Brazil, through a narrative review of the literature. Method: Considering only original articles that presented some information about Brazilian women's futsal, data were collected on Scielo electronic platforms (Scientific Electronic Library Online), on the VHL Regional Portal and Portal Periódicos (CAPES). The initial data search yielded 589 studies, and all were imported into Endnote version 7.0 for screening, only 36 met the eligibility criteria. Results: The studies covered eight different themes and these findings reveal the huge difference that still exists between genders in sport. However, it is possible to identify the growth in the number of publications referring to women's futsal in Brazil in recent years. Discussion: On the main themes investigated, the questions of "Gender" have been inserted in scientific publications because being a woman and playing football means, simultaneously, playing a sport conceived as a social phenomenon. Conclusion: it is concluded that it is necessary that future research be done to enrich the area, make it more visible and minimize the difference between the sexes.
\end{abstract}

Keywords: Female futsal, Brazil, state of art. 


\section{Produção acadêmica em futsal feminino}

${ }^{1,2,3,4}$ Centro Universitário Tabosa de Almeida (ASCES-UNITA), Caruaru, Pernambuco, Brasil

${ }^{2}$ Programa de Pós-graduação em Neuropsiquiatria e Ciências do Comportamento (POSNEURO) na (UFPE), Recife, Pernambuco, Brasil.

$1,2,3,4$ Grupo de Pesquisa em Esporte e Saúde (GPESE) do Centro Universitário Tabosa de Almeida (ASCES-UNITA), Caruaru, Pernambuco, Brasil.

Autor correspondente: ${ }^{4}$ Alison Oliveira da Silva. Rua. Rodopiano Florêncio, n 19, CEP: 55018-420, Bairro Salgado, Caruaru/PE, Brasil.

E-mail: alison.oli@hotmail.com

\section{INTRODUÇÃO}

No Brasil, o futsal é um esporte coletivo com características semelhante ao futebol possuindo suas peculiaridades e tornando-se uma modalidade praticada por um grande número de pessoas. Desde sua criação no ano de 1934, quando ainda era chamado de futebol de salão, o futsal vem se transformando em várias questões técnicas, táticas e regulamentares (FREITAS et al., 2008). Diferentemente do futebol o futsal é caracterizado por uma sucessão de movimentos de alta velocidade, em espaços reduzidos, com variações continuas nas trocas de direções do atleta e da bola e com pausas de recuperação ativas e incompletas (MEDINA et al., 2002).

O futsal desde sua criação foi um fenômeno praticado pelos homens e segundo a Federação Internacional de Futebol Associado (FIFA) praticado em mais de 140 países. Uma realidade diferente para a mesma modalidade praticada pelas mulheres que só em 23 de abril de 1983 foi autorizada pela Federação Internacional de Futebol de Salão (FIFUSA) a prática de futsal feminino. Embora seja uma categoria ampla, o gênero feminino ainda sofre barreiras discriminatórias e machistas que por vezes tornam-se obstáculos para as atletas. As diferenças anatômicas e biológicas têm sido significadas como base explicativa para desigualdades sociais, cujas respostas, entretanto, advém de uma construção histórico-cultural manifestada em crenças religiosas, tabus sociais e aversão à diferença (SIMÕES, KNIJNIK, MACEDO, 2005).

Em estudos realizados no Brasil pelo Ministério do Esporte (2013) observa-se que, aproximadamente, $5 \%$ das mulheres brasileiras praticam futebol e $1 \%$ pratica futsal em momentos de lazer. Nas últimas décadas percebe-se um aumento no número de praticantes do sexo feminino no futsal assim como estudos interessados nesse público, principalmente sobre os desafios e preconceitos (ANJOS, DANTAS, 2016). Porém, a relação do futsal feminino ainda é um tema com poucas informações em estudos de revisões bibliográficas. Com a perspectiva de contribuir com a consolidação deste assunto na literatura e gerar debates e reflexões que possam melhorar seu desenvolvimento também no âmbito empírico, a partir do fornecimento de subsídios para discuti-lo e aprimorá-lo.

Sendo assim, a fim de mapear e discutir os diferentes campos de conhecimento apresentados na literatura, pretendendo entender quais aspectos foram favorecidos em diferentes épocas e lugares o objetivo deste trabalho é mapear a produção científica sobre futsal feminino no Brasil. 


\section{Produção acadêmica em futsal feminino}

\section{MÉTODO}

O presente estudo caracteriza-se, quanto aos fins, como de caráter qualitativo e descritivo e, quanto aos meios, utiliza-se de pesquisa bibliográfica, definindo-o como um estudo de revisão narrativa (GIL, 1995). A coleta de dados foi efetuada na base de dados eletrônicos Scielo (Scientific Electronic Library Online), no Portal Regional da BVS e Portal Periódico (CAPES), além disso, foi realizada uma busca reversa considerando as referências dos estudos selecionados para complementar a respectiva seleção de artigos.

A coleta dos artigos foi feita utilizando as palavras-chave: "futsal"; "feminino"; "mulheres" e "Brasil". Para a busca e seleção dos artigos, foram utilizados os descritores associados com os termos booleanos "AND" e "OR", nas bases de dados utilizadas na busca. Os artigos que apresentaram esses termos no seu título, resumo ou palavras-chave foram selecionados para as análises. Com o objetivo de abranger ao máximo o levantamento realizado, não foi estabelecido limite inferior para a data de publicação dos artigos. O limite superior foi estabelecido até o mês de abril de 2021. Todos os estudos encontrados foram importados para o Endnote versão 7.0 para posterior triagem.

Neste estudo foram considerados apenas artigos originais que relatassem alguma informação sobre o futsal feminino brasileiro e que tivessem acesso livre. Estudos de revisão, resenhas, ponto de vista e resumos publicados em anais de congressos não foram considerados. Na primeira etapa, foram realizadas as leituras dos títulos/resumos e, em seguida, aqueles estudos que pareciam atender aos critérios de inclusão foram lidos na íntegra.

Após a seleção dos artigos, eles foram categorizados, sendo divididos nos anos em que foram publicados e nas principais temáticas investigadas. Para classificação quanto as temáticas investigadas foram atribuídas em oito diferentes categorias (Treinamento esportivo; Psicologia; Gênero; Fisiologia; Publicações científicas; Lesões esportivas; Questões sociais; Cineantropometria).

Os títulos, palavras-chave e resumos foram utilizados para definir a categoria dos artigos; quando insuficientes, realizamos a leitura completa dos artigos. A categorização de cada artigo foi feita por dois avaliadores de maneira independente. Quando não houve concordância entre eles, um terceiro avaliador também realizou a classificação.

O fluxograma do processo de busca, triagem e inclusão dos estudos estão apresentados na figura 1. Utilizando-se as palavras-chave pré-definidas, a busca inicial das bases de dados gerou 589 estudos. 33 estudos foram duplicados, 431 estudos excluídos com base na leitura dos títulos, 48 estudos com base na leitura do resumo/texto completo e 36 estudos atenderam aos critérios pré-estabelecidos. 
Produção acadêmica em futsal feminino

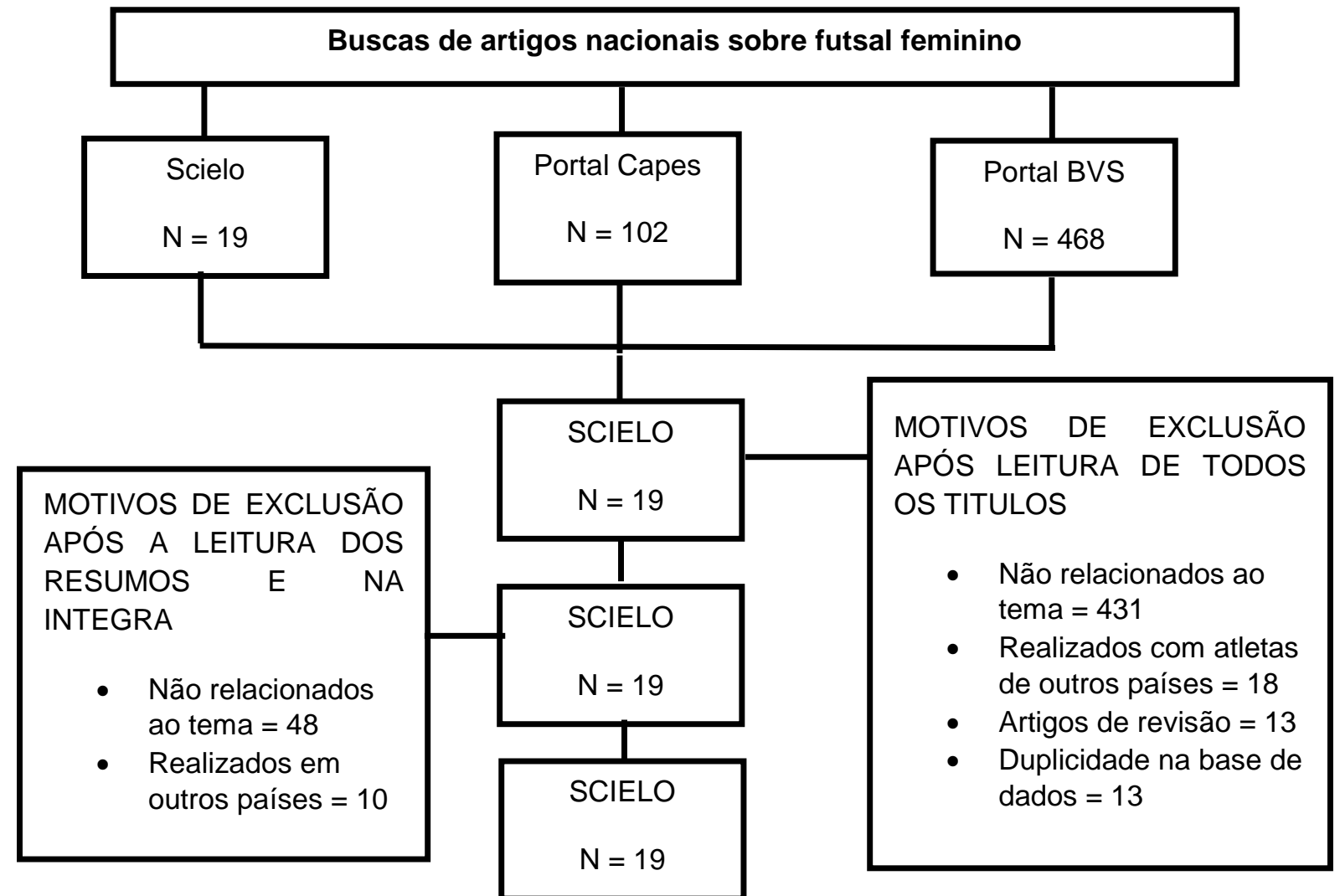

Figura1- Processo de busca dos artigos relacionados ao futsal feminino brasileiro

\section{RESULTADOS E DISCUSSÃO}

Ao todo foram encontrados 36 artigos sobre futsal feminino, publicados em 18 periódicos nacionais. Os artigos estavam indexados em periódicos avaliados em extratos variando de A2 a B5 pela Capes (área
21) no triênio (2013-2016). A Tabela 1 apresenta a quantidade de artigos sobre futsal feminino $e$ as principais temáticas investigadas.

Tabela 1 - Características dos artigos nacionais sobre futsal feminino.

\begin{tabular}{|c|c|c|c|c|c|}
\hline Autores & Título do artigo & Título da r & $\begin{array}{c}\text { Ano de } \\
\text { publicação }\end{array}$ & $\begin{array}{c}\text { Estrato } \\
\text { Qualis } \\
\end{array}$ & $\begin{array}{l}\text { Temáticas } \\
\text { investigadas }\end{array}$ \\
\hline
\end{tabular}

\begin{tabular}{|c|c|c|c|c|c|}
\hline $\begin{array}{l}\text { Pinto et al., } \\
\text { (2020). }\end{array}$ & $\begin{array}{l}\text { Efeitos dos jogos } \\
\text { reduzidos sobre os } \\
\text { marcadores } \\
\text { Psicofisiológicos de } \\
\text { atletas de futsal } \\
\text { feminino }\end{array}$ & $\begin{array}{c}\text { Revista Brasileira } \\
\text { de Ciência e } \\
\text { Movimento }\end{array}$ & 2020 & B2 & $\begin{array}{c}\text { Treinamento } \\
\text { esportivo }\end{array}$ \\
\hline $\begin{array}{l}\text { Ferreira et al., } \\
(2020) .\end{array}$ & $\begin{array}{c}\text { Idade relativa em } \\
\text { atletas de futsal } \\
\text { feminino: implicações } \\
\text { no perfil } \\
\text { antropométrico e } \\
\text { titularidade }\end{array}$ & $\begin{array}{c}\text { Revista Brasileira } \\
\text { de Medicina do } \\
\text { Esporte }\end{array}$ & 2020 & $\mathrm{~A} 2$ & Fisiologia \\
\hline
\end{tabular}




\section{Produção acadêmica em futsal feminino}

\begin{tabular}{|c|c|c|c|c|c|}
\hline $\begin{array}{l}\text { Zanatta, } \\
\text { Soares, } \\
\text { Pasqualotti } \\
\text { (2020). }\end{array}$ & $\begin{array}{l}\text { Velocidade da bola } \\
\text { após o chute, nas } \\
\text { categorias de base } \\
\text { no futsal feminino }\end{array}$ & $\begin{array}{l}\text { Revista Brasileira } \\
\text { de Futsal e Futebol }\end{array}$ & 2020 & B4 & $\begin{array}{l}\text { Treinamento } \\
\text { Esportivo }\end{array}$ \\
\hline $\begin{array}{l}\text { Marenucci et } \\
\text { al., (2020). }\end{array}$ & $\begin{array}{l}\text { Ansiedade pré- } \\
\text { competitva, coesão } \\
\text { de grupo e resiliência } \\
\text { em atletas de futsal } \\
\text { feminino }\end{array}$ & $\begin{array}{l}\text { Revista Brasileira } \\
\text { de Futsal e Futebol }\end{array}$ & 2020 & B4 & Psicologia \\
\hline $\begin{array}{l}\text { Silva et al., } \\
\text { (2019). }\end{array}$ & $\begin{array}{c}\text { O relacionamento } \\
\text { com o treinador pode } \\
\text { afetar a motivação de } \\
\text { atletas paranaenses } \\
\text { de futsal? }\end{array}$ & $\begin{array}{c}\text { Revista Saúde e } \\
\text { Pesquisa }\end{array}$ & 2019 & B4 & Psicologia \\
\hline $\begin{array}{l}\text { Queiroga, } \\
\text { (2019). }\end{array}$ & $\begin{array}{c}\text { Comparação entre } \\
\text { duas gerações para } \\
\text { verificar as } \\
\text { alterações } \\
\text { morfológicas em } \\
\text { atletas femininas de } \\
\text { futsal em um período } \\
\text { de } 10 \text { anos }\end{array}$ & $\begin{array}{l}\text { Revista Brasileira } \\
\text { de } \\
\text { Cineantropometria } \\
\text { \& Desempenho } \\
\text { Humano }\end{array}$ & 2019 & B1 & Cineantropometria \\
\hline $\begin{array}{c}\text { Cosvoski, } \\
\text { Antunes } \\
\text { (2019). }\end{array}$ & $\begin{array}{l}\text { Síndrome de Burnout } \\
\text { em atletas de futsal } \\
\text { feminino } \\
\text { universitárias: um } \\
\text { estudo comparativo }\end{array}$ & Pensar a Prática & 2019 & B2 & Psicologia \\
\hline $\begin{array}{l}\text { Kassiano et } \\
\text { al., (2019). }\end{array}$ & $\begin{array}{c}\text { Respostas } \\
\text { neuromusculares e } \\
\text { fisiológicas durante o } \\
\text { jogo em atletas de } \\
\text { futsal feminino }\end{array}$ & $\begin{array}{c}\text { Journal of Physical } \\
\text { Education }\end{array}$ & 2019 & B5 & Fisiologia \\
\hline $\begin{array}{l}\text { Caldas et al., } \\
\text { (2019). }\end{array}$ & $\begin{array}{c}\text { Análise dos } \\
\text { fundamentos } \\
\text { técnicos defensivos } \\
\text { durante competição } \\
\text { de futsal feminino }\end{array}$ & $\begin{array}{l}\text { Revista Brasileira } \\
\text { de Futsal e Futebol }\end{array}$ & 2019 & B4 & $\begin{array}{l}\text { Treinamento } \\
\text { Esportivo }\end{array}$ \\
\hline $\begin{array}{l}\text { Sousa Filho, } \\
(2018) .\end{array}$ & $\begin{array}{l}\text { Prevalência e perfil } \\
\text { de lesões esportivas } \\
\text { em atletas de futsal } \\
\text { feminino nos jogos } \\
\text { universitários } \\
\text { brasileiros }\end{array}$ & $\begin{array}{l}\text { Revista Brasileira } \\
\text { de Futsal e Futebol }\end{array}$ & 2018 & B4 & Lesões esportivas \\
\hline $\begin{array}{l}\text { Caldas et al., } \\
\text { (2018). }\end{array}$ & $\begin{array}{c}\text { A RBFF é } \\
\text { considerada o } \\
\text { periódico mais } \\
\text { relevante em } \\
\text { publicações } \\
\text { científicas acerca do } \\
\text { futebol e futsal } \\
\text { feminino na área da } \\
\text { educação física }\end{array}$ & $\begin{array}{l}\text { Revista Brasileira } \\
\text { de Futsal e Futebol }\end{array}$ & 2018 & B4 & $\begin{array}{l}\text { Publicações } \\
\text { científicas }\end{array}$ \\
\hline
\end{tabular}




\section{Produção acadêmica em futsal feminino}

\begin{tabular}{|c|c|c|c|c|c|}
\hline $\begin{array}{c}\text { Souza, Martins } \\
(2018) .\end{array}$ & $\begin{array}{l}\text { O paradoxo da } \\
\text { profissionalização do } \\
\text { futsal feminino no } \\
\text { Brasil: entre o } \\
\text { esporte e outra } \\
\text { carreira }\end{array}$ & Pensar a Prática & 2018 & B2 & Questão social \\
\hline $\begin{array}{l}\text { Queiroga et } \\
\text { al., (2018). }\end{array}$ & $\begin{array}{l}\text { Perfil morfológico de } \\
\text { atletas titulares e } \\
\text { reservas de futsal } \\
\text { feminino }\end{array}$ & $\begin{array}{c}\text { Journal of Physical } \\
\text { Education }\end{array}$ & 2018 & B5 & Cineantropometria \\
\hline $\begin{array}{l}\text { Silva, Nazario, } \\
\text { (2018). }\end{array}$ & $\begin{array}{l}\text { Mulheres atletas de } \\
\text { futsal: estratégias de } \\
\text { resistência e } \\
\text { permanência no } \\
\text { esporte }\end{array}$ & $\begin{array}{l}\text { Revista Estudos } \\
\text { Feministas }\end{array}$ & 2018 & B3 & Gênero \\
\hline $\begin{array}{c}\text { Junior, Alves } \\
\text { (2017). }\end{array}$ & $\begin{array}{l}\text { The relative age } \\
\text { effect on Brazilian } \\
\text { Elite Futsal: Men and } \\
\text { Women Scenarios }\end{array}$ & $\begin{array}{l}\text { Motriz: Revista de } \\
\text { Educação Física }\end{array}$ & 2017 & B1 & Gênero \\
\hline $\begin{array}{l}\text { Marques, } \\
\text { Voser, } \\
\text { Tartaruga } \\
\text { (2016). }\end{array}$ & $\begin{array}{l}\text { Perfil antropométrico } \\
\text { de atletas } \\
\text { universitárias de } \\
\text { futsal feminino } \\
\text { conforme a função } \\
\text { tática }\end{array}$ & $\begin{array}{c}\text { Revista Brasileira } \\
\text { de Nutrição } \\
\text { Esportiva }\end{array}$ & 2016 & B3 & Cineantropometria \\
\hline
\end{tabular}

\begin{tabular}{|c|c|c|c|c|c|}
\hline $\begin{array}{l}\text { Soares e al., } \\
(2016) .\end{array}$ & $\begin{array}{c}\text { Avaliação da } \\
\text { ingestão calórica e } \\
\text { composição corporal } \\
\text { de atletas de futsal } \\
\text { feminino do } \\
\text { município de } \\
\text { Guarapuava-Paraná }\end{array}$ & $\begin{array}{l}\text { Revista Brasileira } \\
\text { de Futsal e Futebol }\end{array}$ & 2016 & B4 & Fisiologia \\
\hline $\begin{array}{l}\text { Rocha, Nunes, } \\
\text { Vieira (2015). }\end{array}$ & $\begin{array}{c}\text { Periodização com } \\
\text { cargas seletivas } \\
\text { atenua os distúrbios } \\
\text { bioquímicos e } \\
\text { melhora o } \\
\text { desempenho físico } \\
\text { em jogadoras de } \\
\text { futsal durante a } \\
\text { temporada } \\
\text { competitiva }\end{array}$ & $\begin{array}{l}\text { Motriz: Revista de } \\
\text { Educação Física }\end{array}$ & 2015 & B1 & $\begin{array}{l}\text { Treinamento } \\
\text { Esportivo }\end{array}$ \\
\hline
\end{tabular}

\begin{tabular}{|c|c|c|c|c|c|}
\hline $\begin{array}{l}\text { David, } \\
\text { Picanço, } \\
\text { Reichert, } \\
\text { (2014). }\end{array}$ & $\begin{array}{l}\text { Análise de fatores } \\
\text { determinantes do gol } \\
\text { no futsal feminino }\end{array}$ & $\begin{array}{l}\text { Revista Brasileira } \\
\text { de Futsal e Futebol }\end{array}$ & 2014 & B4 & $\begin{array}{l}\text { Treinamento } \\
\text { esportivo }\end{array}$ \\
\hline $\begin{array}{l}\text { Fonteles et al., } \\
\text { (2014). }\end{array}$ & $\begin{array}{c}\text { Avaliação isocinética } \\
\text { da musculatura } \\
\text { extensora e flexora } \\
\text { do joelho de atletas } \\
\text { de futsal feminino }\end{array}$ & $\begin{array}{l}\text { Revista Brasileira } \\
\text { de Futsal e Futebol }\end{array}$ & 2014 & B4 & Cineantropometria \\
\hline
\end{tabular}




\begin{tabular}{|c|c|c|c|c|c|}
\hline $\begin{array}{c}\text { Moreira, } \\
\text { Navarro, } \\
\text { Zanetti (2014). }\end{array}$ & $\begin{array}{l}\text { Perfil de IMC, } \\
\text { Somatotipo, } \\
\text { Agilidade e } \\
\text { resistência } \\
\text { anaeróbica láctica de } \\
\text { atletas de futsal } \\
\text { feminino das } \\
\text { categorias sub } 15, \\
17,19 \text { e adulto }\end{array}$ & $\begin{array}{l}\text { Revista Brasileira } \\
\text { de Futsal e Futebol }\end{array}$ & 2014 & B4 & Cineantropometria \\
\hline $\begin{array}{c}\text { Altmann, Reis } \\
\text { (2013). }\end{array}$ & $\begin{array}{l}\text { Futsal feminino na } \\
\text { América do Sul: } \\
\text { trajetórias de } \\
\text { enfrentamentos e de } \\
\text { conquistas }\end{array}$ & $\begin{array}{c}\text { MOVIMENTO } \\
\text { (UFRGS. ONLINE) }\end{array}$ & 2013 & A2 & Gênero \\
\hline $\begin{array}{c}\text { Rocha, } \\
\text { Waltrick, } \\
\text { Venera (2013). }\end{array}$ & $\begin{array}{c}\text { Composição } \\
\text { corporal, qualidades } \\
\text { físicas e } \\
\text { características } \\
\text { dermatoglíficas das } \\
\text { atletas da seleção } \\
\text { brasileira de futsal } \\
\text { feminino por posição } \\
\text { de jogo }\end{array}$ & $\begin{array}{l}\text { Revista Brasileira } \\
\text { de Futsal e Futebol }\end{array}$ & 2013 & B4 & Cineantropometria \\
\hline $\begin{array}{c}\text { Silveira, } \\
\text { Stigger (2013). }\end{array}$ & $\begin{array}{l}\text { Jogando com as } \\
\text { feminilidades: um } \\
\text { estudo etnográfico } \\
\text { em um time de futsal } \\
\text { feminino de Porto } \\
\text { Alegre }\end{array}$ & $\begin{array}{c}\text { Revista Brasileira } \\
\text { de Ciências do } \\
\text { Esporte }\end{array}$ & 2013 & B1 & Gênero \\
\hline $\begin{array}{l}\text { Ferreira et al., } \\
\text { (2012). }\end{array}$ & $\begin{array}{c}\text { Influência do } \\
\text { treinamento de futsal } \\
\text { na composição } \\
\text { corporal e na } \\
\text { potência de membros } \\
\text { inferiores em atletas } \\
\text { do sexo feminino }\end{array}$ & $\begin{array}{l}\text { Revista Brasileira } \\
\text { de Futsal e Futebol }\end{array}$ & 2012 & B4 & $\begin{array}{l}\text { Treinamento } \\
\text { esportivo }\end{array}$ \\
\hline $\begin{array}{c}\text { Gayardo, } \\
\text { Matana, Silva } \\
\text { (2012). }\end{array}$ & $\begin{array}{l}\text { Prevalência de } \\
\text { lesões em atletas do } \\
\text { futsal feminino } \\
\text { brasileiro: um estudo } \\
\text { retrospectivo }\end{array}$ & $\begin{array}{c}\text { Revista Brasileira } \\
\text { de Medicina do } \\
\text { Esporte }\end{array}$ & 2012 & A2 & Lesões esportivas \\
\hline
\end{tabular}

\begin{tabular}{|c|c|c|c|c|c|}
\hline $\begin{array}{c}\text { Santana e } \\
\text { Vacario } \\
\text { (2012). }\end{array}$ & $\begin{array}{l}\text { Análise de faltas } \\
\text { combarreira emjogos } \\
\text { defutsal feminino de } \\
\text { alto rendimento }\end{array}$ & Pensar a Prática & 2012 & B2 & $\begin{array}{c}\text { Treinamento } \\
\text { Esportivo }\end{array}$ \\
\hline $\begin{array}{l}\text { Silva et al., } \\
\text { (2011) }\end{array}$ & $\begin{array}{l}\text { Perfil de lesões } \\
\text { desportivas em } \\
\text { atletas de futsal } \\
\text { feminino de Marília }\end{array}$ & Concientiae saúde & 2011 & B2 & $\begin{array}{l}\text { Lesões } \\
\text { desportivas }\end{array}$ \\
\hline $\begin{array}{l}\text { Ramos, } \\
\text { Oliveira, } \\
\text { Almeida } \\
\text { (2011). }\end{array}$ & $\begin{array}{c}\text { Avaliação da } \\
\text { concentração de } \\
\text { lactato em dois } \\
\text { testes anaeróbicos }\end{array}$ & $\begin{array}{l}\text { Revista Brasileira } \\
\text { de Prescrição e } \\
\text { Fisiologia do } \\
\text { Exercício }\end{array}$ & 2011 & B3 & Cineantropometria \\
\hline
\end{tabular}




\begin{tabular}{|c|c|c|c|c|c|}
\hline & $\begin{array}{l}\text { indiretos: estudo } \\
\text { comparado em } \\
\text { atletas juvenis de } \\
\text { futsal feminino }\end{array}$ & & & & \\
\hline $\begin{array}{l}\text { Baldaço et al., } \\
(2010) .\end{array}$ & $\begin{array}{c}\text { Análise do } \\
\text { treinamento } \\
\text { proprioceptivo no } \\
\text { equilíbrio de atletas } \\
\text { de futsal feminino }\end{array}$ & $\begin{array}{l}\text { Revista } \\
\text { Fisioterapia em } \\
\text { Movimento }\end{array}$ & 2010 & B1 & $\begin{array}{l}\text { Treinamento } \\
\text { esportivo }\end{array}$ \\
\hline $\begin{array}{l}\text { Silva, } \\
\text { Machinski } \\
\text { (2010). }\end{array}$ & $\begin{array}{l}\text { Futsal masculino e } \\
\text { feminino: a } \\
\text { comparação } \\
\text { motivacional no } \\
\text { município de } \\
\text { Rebouças-PR }\end{array}$ & Revista Cinergis & 2010 & B5 & Gênero \\
\hline $\begin{array}{l}\text { Benvenuti et } \\
\text { al,. (2010). }\end{array}$ & $\begin{array}{l}\text { Agility assessment in } \\
\text { female futsal and } \\
\text { soccer players }\end{array}$ & Medicina (Kaunas) & 2010 & B2 & Cineantropometria \\
\hline
\end{tabular}

Rosa, Costa,
Navarro
(2009).
A prática do futsal feminino na formação das jogadoras brasileiras de futebol
Revista Brasileira de Futsal e Futebol

2009

B4

Treinamento esportivo

\begin{tabular}{|c|c|c|c|c|c|}
\hline $\begin{array}{l}\text { Gaion, Vieira, } \\
\text { Silva (2009). }\end{array}$ & $\begin{array}{l}\text { Síndrome pré- } \\
\text { menstrual e } \\
\text { percepção de } \\
\text { impacto no } \\
\text { desempenho } \\
\text { esportivo de atletas }\end{array}$ & $\begin{array}{c}\text { Revista Brasileira } \\
\text { de } \\
\text { Cineantropometria } \\
\text { \& Desempenho } \\
\text { Humano }\end{array}$ & 2009 & B1 & Fisiologia \\
\hline
\end{tabular}

\begin{tabular}{|c|c|c|c|c|c|}
\hline $\begin{array}{l}\text { Queiroga, } \\
\text { Ferreira, } \\
\text { Romanzini } \\
\text { (2005). }\end{array}$ & $\begin{array}{l}\text { Perfil antropométrico } \\
\text { de atletas de futsal } \\
\text { feminino de alto nível } \\
\text { competitivo conforme } \\
\text { a função tática } \\
\text { desempenhada no } \\
\text { jogo }\end{array}$ & $\begin{array}{c}\text { Revista Brasileira } \\
\text { de } \\
\text { Cineantropometria } \\
\text { \& Desempenho } \\
\text { Humano }\end{array}$ & 2005 & B1 & Cineantropometria \\
\hline $\begin{array}{c}\text { Santana, Reis } \\
(2003) .\end{array}$ & $\begin{array}{l}\text { Futsal Feminino: } \\
\text { perfil e implicações } \\
\text { pedagógicas }\end{array}$ & $\begin{array}{l}\text { Revista Brasileira } \\
\text { de Ciência e } \\
\text { Movimento }\end{array}$ & 2003 & B2 & Gênero \\
\hline
\end{tabular}

Nos trabalhos encontrados observouse uma quantidade predominante em algumas revistas sobre o futsal feminino, destacando-se a Revista Brasileira de Futsal e Futebol com 11 (onze) publicações no total. A temática mais investigada esteve relacionada ao treinamento esportivo e a cineantropometria, obtendo 9 (nove) estudos de cada um. Observa-se um crescimento no número de publicações nos últimos anos como pode ser observado no quadro 1. 


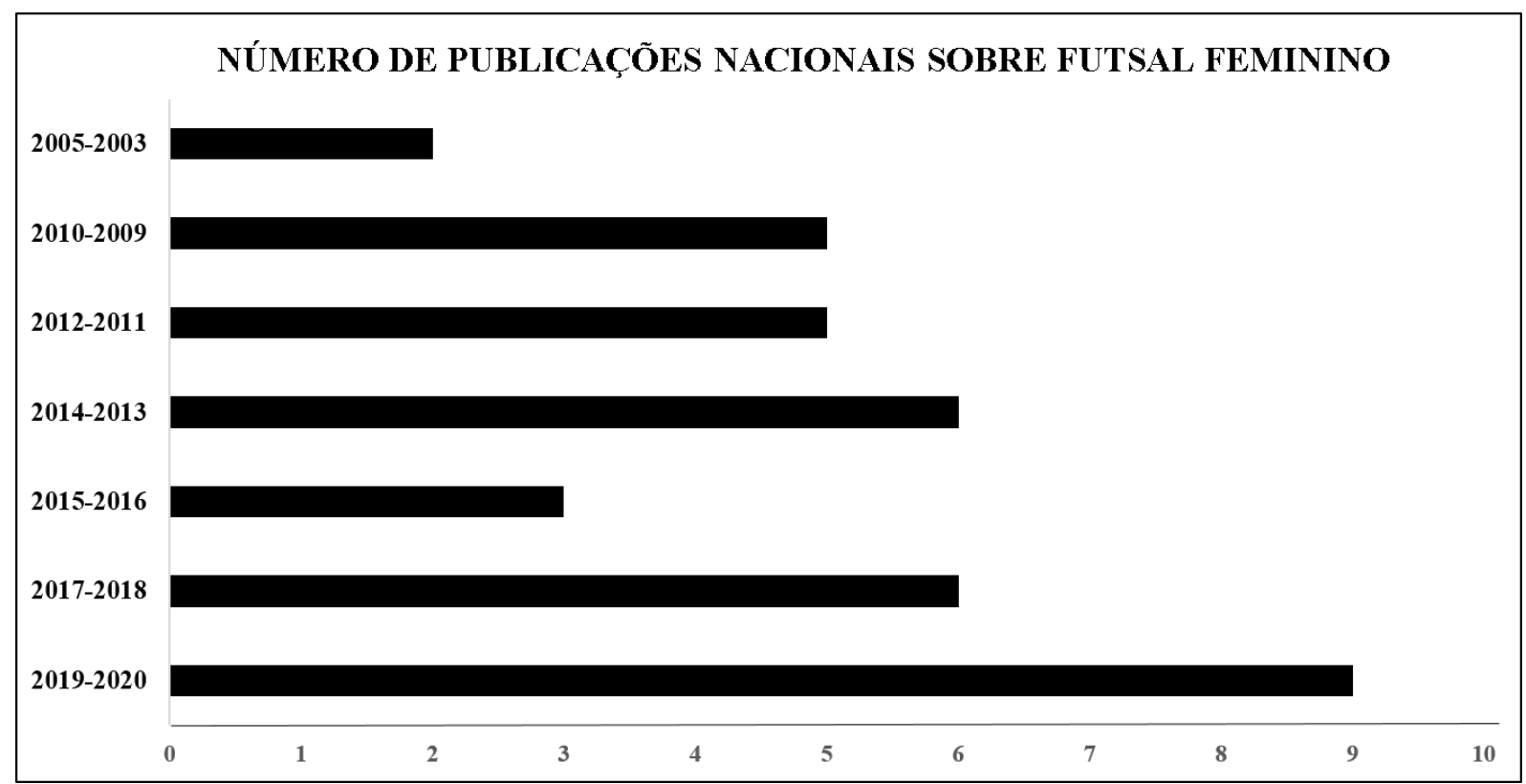

Quadro 1 - Numero de publicações nacionais sobre o Futsal Feminino.

Sobre as principais temáticas investigadas as questões de "Gênero" têm sido inseridas nas publicações científicas, pois ser mulher e jogar futebol significa, simultaneamente, praticar um esporte concebido como fenômeno social e estar à margem daquilo considerado "central" para o sexo feminino (LOURO, 2012). Às vezes mulheres atletas por apresentar um corpo feminino musculoso, adulterado no e pelo esporte, manifestando atributos como força, agressividade e habilidade técnica, são interrogadas, por esses serem elementos culturalmente entendidos como exclusivos masculinos.

Nos artigos encontrados relacionados a gênero grande maioria apresentou nos resultados o futsal como uma participação maior e historicamente mais antiga com o público masculino, sendo recente a atração e prática das mulheres. Em um estudo feito por Silva, Machinski (2010) mostrou que em uma análise de comparação motivacional entre atletas de ambos os sexos, teve como conclusão que o público feminino quando comparado pode-se observar que a mulher dá mais importância para os fatores que envolvem o reconhecimento delas no esporte e na sociedade e o masculino se dá importância para os fatores de força. Ou seja, embora o futsal nos últimos anos tenha crescido o número de praticantes, as mulheres sempre estiveram em um lado de resistência, em busca de valorização no esporte, mesmo que se seus propósitos sejam apenas vivenciar momentos de lazer.
O treinamento esportivo foi uma temática bastante encontrada nas publicações nacionais, por ser um dos principais meios de adaptação dos estímulos externos de todo atleta, geralmente esse treinamento está relacionado com o objetivo de melhorar todo o desenvolvimento e aumento do rendimento, seja ele desde um controle de equilíbrio postural, para aspectos determinantes do gol, todos com intuito de preparação para o jogo situacional. Segundo Rocha, Nunes, Vieira (2015), a periodização com cargas seletivas é adequada e atende as exigências da modalidade durante a temporada competitiva em jogadoras de futsal feminino.

Com relação aos artigos sobre a cineantropometria, observou uma quantidade variada de estudos. Por exemplo, Ramos, Oliveira, Almeida (2011) em seu estudo compararam as concentrações de lactato em dois testes de campo indiretos: o Teste "Rast" e o Teste de "40 segundos", aplicados em dez jogadoras de futsal feminino. Foi coletada a concentração de lactato sanguíneo em ambos os testes: repouso, após 10 segundos da realização do teste e após 8 minutos com repouso passivo. Com base nos resultados pode-se concluir que não houve diferença significativa entre os dois testes indiretos e que considerando a comparação do impacto metabólico anaeróbico lático nas atletas, ambos podem ser aplicados para avaliar a capacidade anaeróbica em jogadores de futsal.

Queiroga et al., (2018) compararam as características morfológicas de atletas de 


\section{Produção acadêmica em futsal feminino}

futsal feminino titulares e reservas de alto nível competitivo. Participaram 115 atletas, 60 titulares e 55 reservas pertencentes a 10 equipes que disputaram da XX Taça Brasil de Clubes, divisão especial. Medidas antropométricas foram obtidas com a finalidade de caracterizar e determinar o somatório corporal. Os resultados revelaram que as atletas titulares são mais velhas, possuem maior tempo de prática, menor percentual de gordura e diâmetro do fêmur do que as reservas, porém, as duas últimas perdem a significância ao serem ajustadas pelo tempo de prática. Considerando que a composição corporal e a experiência esportiva são atributos associados ao desempenho, as diferenças observadas entre as atletas titulares e reservas podem contribuir para a tomada de decisão do treinador na formação da equipe titular em jogos de futsal feminino.

Em um estudo feito por Souza e Martins (2018) com o intuito de analisar a relação entre o perfil socioeconômico, a formação esportiva e a carreira esportiva, observou que a carreira no futsal de mulheres é pouco estruturada, o que ajuda a compreender o motivo pelo qual o perfil das atletas é formado por mulheres de famílias de baixo capital cultural e poder aquisitivo. Para elas, a carreira no futsal constitui um paradoxo, pois não é um projeto de vida em si, mas a fonte de acesso a outro, que pode se consolidar como uma possibilidade de mudança social para elas.

No que se refere às questões psicológicas foram encontrados temas direcionados a relação do treinador com a motivação de atletas e ansiedade précompetitiva, coesão de grupo e resiliência. Marenucci et al., (2020) afirmam que as atletas do futsal feminino paranaense se mostram motivadas intrinsecamente para suas práticas

\section{CONCLUSÃO}

A partir desse mapeamento foi possível identificar o crescimento no número de publicações referidas ao futsal feminino no Brasil nos últimos anos, como também destacar quais temáticas foram mais discutidas atualmente no cenário nacional. É esportivas, percebem um relacionamento com o treinador baseado na confiança, respeito e comportamentos amigáveis. Já voltado a ansiedade pré-competitiva, é constatado segundo Silva et al., (2019) que as atletas apresentaram um maior nível de ansiedade no primeiro jogo quando comparados aos demais, bem como elevados níveis de coesão de grupo e resiliência.

Os aspectos fisiológicos obtiveram alguns temas achados, referente à ingestão calórica e composição corporal; respostas neuromusculares e fisiológicas durante o jogo; e o efeito da idade relativa em atletas e sua influência no perfil antropométrico e na titularidade. Sabemos que modalidade do futsal é uma das mais praticadas no Brasil, onde os atletas devem obter uma alimentação equilibrada com o fornecimento suficiente de energia e nutrientes. No estudo de Soares e al., (2016) verificaram-se inadequações quanto ao consumo de energia e macronutrientes em toda a população, e percentual de gordura distante do ideal, enfatizando assim a necessidade da inserção do profissional nutricionista no âmbito esportivo, com o intuito de garantir melhor alimentação e desempenho a essas competidoras.

Considerado um esporte composto de altos níveis de habilidades, táticas e de grande demanda por desempenho físico, devido às características de contato físico constante, coloca as atletas em considerável risco de lesões esportivas. Sendo assim estudos observaram as características e identificação para prevalência dos locais e tipos de lesões. Gayardo, Matana, Silva (2012) e Silva et al., (2011) verificaram que a maior parte das lesões ocorre nos membros inferiores, enfatizando os segmentos do joelho, coxa e com alta incidência no tornozelo.

de suma importância poder contribuir com pesquisas referidas a esse conteúdo, com o intuito de somar em uma área que ainda é coberta de discriminações. Porém, se faz necessário que pesquisas futuras sejam feitas para enriquecer a área e torná-la mais visível. 


\section{REFERÊNCIAS}

ALMEIDA, T. R. Fortes, aguerridas e femininas: um olhar etnográfico sobre as mulheres praticantes de rugby em um clube de Porto Alegre 2008. Dissertação (Mestrado em Ciências do Movimento Humano), Escola de Educação Física, UFRGS, Porto Alegre.

ALTMANN, H; REIS, H. H. B. Futsal feminino na América do Sul: trajetórias de enfrentamento e de conquistas. Movimento (ESEFID/UFRGS), v. 19, n. 3, p. 211-232, 2013.

ANJOS, L. A; DANTAS, M. M. Pesquisadoras do futebol: discussões a partir de duas trajetórias. Esporte e Sociedade, n. 28, 2021.

BALDAÇO, F. B, et al. Análise do treinamento proprioceptivo no equilíbrio de atletas de futsal feminino. Fisioterapia em Movimento, v. 23, n. 2, p. 183-192, 2010.

BENVENUTI, C. et al Agility assessment in female futsal and soccer players. Medicina, v. 46, n. 6, p. 415, 2010.

CALDAS, E. S, et al. A RBFF é considerada o periódico mais relevante em publicações científicas acerca do Futebol e Futsal feminino na área de Educação Física. RBFF-Revista Brasileira de Futsal e Futebol, v. 10, n. 39, p. 390-391, 2018.

CALDAS, E. S, et al. Análise dos fundamentos técnicos defensivos durante competições de Futsal Feminino. RBFF-Revista Brasileira de Futsal e Futebol, v. 11, n. 44, p. 324-327, 2019.

COSVOSKI, T. et al. Síndrome de Burnout em atletas de futsal feminino universitárias: um estudo comparativo. Pensar a Prática, v. 22, 2019.

DAVID, G. B; PICANÇO, L. M; REICHERT, F. F. Análise de fatores determinantes do gol no futsal feminino. RBFF-Revista Brasileira de Futsal e Futebol, v. 6, n. 19, 2014.

FERREIRA, G. F, et al. Influência do treinamento de futsal na composição corporal e na potência de membros inferiores em atletas do sexo feminino. RBFF-Revista Brasileira de Futsal e Futebol, v. 4, n. 13, 2012.

FERREIRA, S. A, et al. Relative age in female futsal athletes: implications on anthropometric profile and starter status. Revista Brasileira de Medicina do Esporte, v. 26, n. 1, p. 34-38, 2020.

FIGUEIRA, M. L. M. Skate para Meninas: modos de se fazer ver em um esporte em construção. 2008. 247 p. Tese (Doutorado em Ciências do Movimento Humano), Escola de Educação Física, Universidade Federal do Rio Grande do Sul, Porto Alegre.

FIGUEIRA, M. L. M; GOELLNER, S. V. " Quando você é excluída, você faz o seu": mulheres e skate no Brasil. Cadernos pagu, n. 41, p. 239-264, 2013.

FONTELES, A. I, et al. Avaliação isocinética da musculatura extensora e flexora do joelho de atletas de futsal feminino. RBFF-Revista Brasileira de Futsal e Futebol, v. 6, n. 20, p. 3, 2014.

FREITAS, D. C.; HENRIQUE, J; NOLASCO, R.C. Aspectos técnicos, táticos e regulamentares do futsal sob a ótica de treinadores experts. Revista digital. Buenos Aires, v. 13, 2008.

GAION, P. A; VIEIRA, L. F; SILVA C. M. L. Síndrome pré-menstrual e percepção de impacto no desempenho esportivo de atletas brasileiras de futsal. Revista Brasileira de Cineantropometria \& Desempenho Humano, v. 11, n. 1, p. 73-80, 2009.

GAYARDO, A; MATANA, S. B; SILVA, M. R. Prevalência de lesões em atletas do futsal feminino brasileiro: um estudo retrospectivo. Revista Brasileira de Medicina do Esporte, v. 18, n. 3, p. 186189, 2012. 


\section{Produção acadêmica em futsal feminino}

JÚNIOR, V. R. M; ALVES, I. V. G; The relative age effect on Brazilian elite futsal: Men and women scenarios. Motriz: Revista de Educação Física, v. 23, 2018.

KASSIANO, W, et al. Respostas neuromusculares e fisiológicas durante o jogo em atletas de futsal feminino. Journal of Physical Education, v. 30, n. 1, 2019.

KIMMEL, M. A produção simultânea de masculinidades hegemônicas e subalternas. Horizontes antropológicos, v. 4, n. 9, p. 103-117, 1998

MARENUCCI, N. R, et al. Ansiedade pré-competitiva, coesão de grupo e resiliência em atletas de Futsal feminino. RBFF-Revista Brasileira de Futsal e Futebol, v. 12, n. 48, p. 195-201, 2020.

MARQUES, P. A; VOSER, R. C; TARTARUGA, L. A. P; Perfil antropométrico de atletas universitárias de futsal feminino conforme a função tática. Revista Brasileira de Nutrição Esportiva, v. 10, n. 56, p. 216-221, 2016.

MEDINA, J. A.; SALILLAS, L. G.; VIRÓN, P. C.; MARQUETA, P. M Necessitats cardiovasculars i metabòliques del futbol sala: anàlisi de la competició. Apunts. Educación física y sports, v. 1, n. 67, p. 45-51, 2002.

MILISTETD, M; IGNACHEWSKI, W. L, et al. Análise das características antropométricas, fisiológicas e técnicas de jovens praticantes de futsal de acordo com sua função de jogo. Revista Brasileira de Ciência e Movimento, v. 22, n. 4, p. 27-36, 2014.

MOREIRA, M. A; NAVARRO, A. C; ZANETTI, M. C. Perfil do IMC, Somatotipo, Agilidade e Resistência anaeróbica láctica de atletas de futsal feminino das categorias sub 15, 17, 19 e adulto. RBFF-Revista Brasileira de Futsal e Futebol, v. 6, n. 19, 2014.

PINTO, J. C. B et al. Efeitos dos jogos reduzidos sobre os marcadores psicofisiológicos de atletas de futsal feminino. Revista Brasileira de Ciência e Movimento, p. 69-77, 2020.

QUEIROGA, M. R, et al. Comparação entre duas gerações para verificar as alterações morfológicas em atletas de futsal feminino em um período de 10 anos. Revista Brasileira de Cineantropometria \& Desempenho Humano, v. 21, 2019.

QUEIROGA, M. R, et al. Perfil morfológico de atletas titulares e reservas de futsal feminino. Journal of Physical Education, v. 29, n. 1, 2018.

QUEIROGA, M. R; FERREIRA, S. A. ROMANZINI, M. Perfil antropométrico de atletas de futsal feminino de alto nível competitivo conforme a função tática desempenhada no jogo. Revista Brasileira de Cineantropometria e Desempenho Humano. ISSN, v. 1415, p. 8426, 2005.

RAMOS, V. G; OLIVEIRA, H. G; ALMEIDA, A. L. A. R. Avaliação da concentração de lactato em dois testes anaeróbicos indiretos: estudo comparado em atletas juvenis de futsal feminino. RBPFEXRevista Brasileira de Prescrição e Fisiologia do Exercício, v. 5, n. 27, 2011.

ROCHA, R. E. R; NUNES, E. A; VENERA, G. D. Periodización con cargas selectivas atenúa desórdenes bioquímicos y mejora el desempeño físico en jugadoras de futsal femenino durante etapa competitiva. Motriz: Revista de Educação Física, v. 21, n. 2, p. 158-167, 2015.

ROCHA, R. E. R; WALTRICK, T; VENERA, G. D. Composição corporal, qualidade física e características dermatoglíficas das atletas da seleção Brasileira de futsal feminino por posição de jogo. RBFF-Revista Brasileira de Futsal e Futebol, v. 5, n. 17, 2013.

ROSA, C. F; COSTA, N. G. R; NAVARRO, A. C; A prática do futsal feminino na formação das jogadoras brasileiras de futebol. RBFF-Revista Brasileira de Futsal e Futebol, v. 1, n. 2, p. 9, 2009.

SALLES-COSTA, R, et al. Gênero e prática de atividade física de lazer. Cadernos de Saúde Pública, v.19, n. 2, p. S325-S333, 2003. 


\section{Produção acadêmica em futsal feminino}

SANTANA, W. C; REIS, H. H. B. H B. Futsal feminino: perfil e implicações pedagógicas. Revista Brasileira de Ciência e Movimento, v. 11, n. 4, p. 45-50, 2003.

SANTANA, W. C; VACARIO, E. A. Análise de faltas com barreira em jogos de futsal feminino de alto rendimento. Pensar a Prática, v. 15, n. 3, 2012.

SILVA, A. L. S; NAZÁRIO, P. A; Mulheres atletas de futsal: estratégias de resistência e permanência no esporte. Revista Estudos Feministas, v. 26, n. 1, 2018.

SILVA, D. A. P; MACHINSKI, P. R. Futsal masculino e feminino: a comparação motivacional no município de Rebouças-PR. Cinergis, v. 11, n. 1, 2010.

SILVA, F. M, et al. Perfil de lesões desportivas em atletas de futsal feminino de Marília. ConScientiae Saúde, v. 10, n. 2, p. 249-255, 2011.

SILVA, T. N, et al. O relacionamento com o treinador pode afetar a motivação de atletas paranaenses de futsal? Saúde e Pesquisa, v. 12, n. 1, p. 29-38, 2019.

SILVEIRA, R; STIGGER, M. P. Jogando com as feminilidades: um estudo etnográfico em um time de futsal feminino de Porto Alegre. Revista Brasileira de Ciências do Esporte, v. 35, n. 1, p. 179-194, 2013.

SIMÕES, A. C; KNIJNIK, J. D; MACEDO, L. L. O ser mulher no esporte de competição: a mulher e a busca dos limites no esporte de rendimento. Revista virtual e Artigos. Natal/RN, v. 3, n. 5, 2005.

SOARES, B. M, et al. Avaliação da ingestão calórica e composição corporal de atletas de futsal feminino do município de Guarapuava-Paraná. RBFF-Revista Brasileira de Futsal e Futebol, v. 8, n. 29, p. 129-141, 2016.

SOUZA FILHO, L. F. M, et al. Prevalência e perfil de lesões esportivas em atletas de Futsal feminino nos jogos universitários brasileiros. RBFF-Revista Brasileira de Futsal e Futebol, v. 10, n. 41, p. 729-735, 2018.

SOUZA, A. C. F; MARTINS, M.Z; O paradoxo da profissionalização do futsal feminino no Brasil: entre o esporte e outra carreira. Pensar a Prática, v. 21, n. 1, 2018.

SOUZA, G. C, et all. Rosiclea Campos no judô feminino brasileiro. Revista Estudos Feministas, v. 23, n. 2, p. 409-429, 2015.

ZANATTA, A. M; SOARES, B. H; PASQUALO, A; Velocidade da bola após o chute, nas categorias de base no Futsal feminino. RBFF-Revista Brasileira de Futsal e Futebol, v. 12, n. 48, p. 187-194, 2020. 